УДК $81 ’ 23$

DOI 10.25205/1818-7935-2018-16-3-45-55

\author{
А. А. Яковлев \\ Сибирский федеральный университет \\ пр. Свободный, 82a, Красноярск, 660041, Россия \\ mr.koloboque@rambler.ru

\section{ЛИНГВИСТИЧЕСКАЯ ОСНОВА ОБЩЕЙ ТЕОРИИ ЯЗЫКОВОГО СОЗНАНИЯ}

\begin{abstract}
Обсуждаются теоретико-методологические предпосылки для создания общей теории языкового сознания, включая комплекс экспериментов, способных проверить и, возможно, опровергнуть некоторые ее положения. Основная идея такой теории - охват одновременно внешних (социальных) и внутренних (личностных) факторов в их влиянии на язык, рассматриваемый с антропоцентрических позиций. Для общей теории языкового сознания необходимы: 1) теория языка, соединяющая язык как индивидуальное явление, как явление групповое и как систему; 2) универсальные способы описания любых аспектов и форм существования объекта теории; 3) принципы, из которых выводимы феноменологические свойства объекта и методологические характеристики теории. Положения теории и лежащие в их основе экспериментальные исследования позволят фиксировать, каким образом внутренние (эмоции, ценности и т. п.) и внешние (возраст, профессия и т. п.) условия функционирования языка как достояния человека связаны с изменением значений и смыслов слов и их взаимных связей.

Ключевые слова: языковое сознание, антропоцентрическая лингвистика, психолингвистика, значение, личностный смысл.
\end{abstract}

Известно, что определение понятия должно обладать двумя важными свойствами. Во-первых, оно должно фиксировать соответствующую объекту познания систему внутренних и внешних связей, представленных в форме обобщенного идеального объекта, и операций по отображению этих связей. Во-вторых, понятие, являясь обобщением, должно содержать в себе наиболее существенную закономерность, которой подчиняется данное явление, данный предмет изучения.

Одно из самых распространенных в настоящее время определений языкового сознания (далее - ЯС) в целом соответствует первому требованию, но не второму. «Языковое сознание - это знания, ассоциированные с языковыми знаками для овнешнения в процессе общения первичных и вторичных образов сознания. Первичные образы, по А. Н. Леонтьеву, - это знания, формируемые личностью в процессе восприятия объектов реального мира, а вторичные образы - это первичные образы, используемые в качестве перцептивных эталонов при последующих актах восприятия» [Уфимцева, Тарасов, 2009. С. 20]. Такое определение позволяет путём указания выделить предмет изучения (или совокупность предметов) и соответствующую обобщенную схему его основных свойств, но не позволяет предсказывать поведение предмета лишь на основе этой обобщенной схемы, не прибегая к непосредственному оперированию конкретным предметом, не позволяет вообще говорить о том, как изменения во внутренних и / или внешних связях предмета сказываются на его функционировании и его характеристиках. Кроме того, в приведенном определении ЯС дано в общем виде - как неко-

Яковлев А. А. Лингвистическая основа общей теории языкового сознания // Вестн. Новосиб. гос. ун-та. Серия: Лингвистика и межкультурная коммуникация. 2018. Т. 16, № 3. С. 45-55.

ISSN 1818-7935

Вестник НГУ. Серия: Лингвистика и межкультурная коммуникация. 2018. Том 16, № 3

(C) А. А. Яковлев, 2018 
торая целостность, конституирующие единицы и внутренние связи которой из определения не ясны. Но познание некоторого явления - это и есть выявление его внешних и внутренних связей и закономерностей их изменения.

Разнообразные трактовки ЯС связывают его то с языком как индивидуальным явлением, то с языком как явлением социальным: это отражение в индивидуальном сознании внешних по отношению к нему предметов, фиксируемое в языке. В этом нам видится стремление ученых нащупать понятие, которое связывало бы эти два аспекта языка и позволяло бы проследить связь между динамикой языковых явлений, рассматриваемых с групповых позиций и с позиций индивидуальных. Мы намеренно говорим здесь о группе носителей языка, поскольку особенности языка как явления общественного есть наиболее общий случай языка как явления группового, когда границы группы определяются масштабами лингвокультуры в целом, а не профессией, социальным положением и т. п.; лингвокультура есть, таким образом, предел абстрагирования от каких-либо других характеристик группы, кроме языка, которым в той или иной степени владеют входящие в нее индивиды.

Необходимость общего понятия и общей теории продиктована не только теоретическими аргументами, но и эмпирией.

Здесь прежде всего следует назвать работы А. А. Залевской и ее сотрудников по психолингвистическому портретированию лексики [Залевская, 2011. С. 186-213], проводившиеся «на рубеже веков и эпох» и демонстрирующие на обширном материале, как слова приобретают новые и изменяют имеющиеся значения в силу социальных, экономических и политических перипетий. Е. И. Горошко изучала общее и специфическое в ментальных лексиконах представителей разных социальных групп, а именно ассоциативные связи слов в зависимости от половозрастных особенностей людей, условий их жизни, возраста и т. д. [2001. С. 393 461]. Общий вывод ее исследования заключается в том, что социальные и биографические факторы влияют на структуру ассоциативного поля как в количественном, так и в качественном отношении [Там же. С. 491]. Л. П. Иноземцева исследовала особенности реакций на слова преподаватель и препод в их связи с возрастом студентов. Автор связывает выявленную ею разницу с тем, что изменения в системе образования, вызванные включением образования в сферу услуг, резко изменили ожидания и требования студентов, отражающиеся в значениях слов [2012. С. 74-75].

В наших исследованиях [Яковлев и др., 2015; Яковлев, Елизарова (Телешева), 2016] была показана зависимость значений слов от социокультурных и даже географических особенностей жизни людей. В названных исследованиях материал и методика работы с ним различны: от предъявления в качестве стимулов наименований дней недели без учета «внешних» характеристик испытуемых (возраст, пол, социальное положение и т. п.) до предъявления терминов языкознания студентам-лингвистам разных курсов. Однако общий их вывод таков: в слове отражаются не явления окружающей действительности сами по себе, а их образы, преломленные через личностный опыт переживаний и эмоций. В значении слова проявляется и фиксируется своеобразная диалектика между некоторым явлением действительности и его переживанием человеком. Наиболее типичные ситуации взаимодействия с явлениями и предметами отражаются в значении соответствующего слова, но само значение этого слова тоже влияет на отношение человека к тому или иному явлению и его составляющим (следовательно, частично и на деятельность человека в таких ситуациях). Если же опыт группы людей схож в том или ином отношении (например, опыт общения студентов с преподавателями), то в материале ассоциативного эксперимента, проведенного в этой группе, проявляются закономерные тенденции (см. результаты эксперимента в работе [Яковлев, Елизарова (Телешева), 2016] и их проверку и подтверждение в [Яковлев, 2017]).

Актуальность исследований, учитывающих влияние социальных факторов на формирование ментального лексикона, выражается в создании ассоциативных словарей нового типа: «Ассоциативный словарь школьников Саратова и Саратовской области», «Русский региональный ассоциативный словарь-тезаурус ЕВРАС», двухтомный «Русский региональный ассоциативный словарь (Сибирь и Дальний Восток)» и др.

Чрезвычайно важно при таком богатстве экспериментальных исследований иметь общую концепцию ЯС, которая позволяла бы с единых теоретико-методологических позиций объяснять тенденции, проявляющиеся в разном по составу эмпирическом материале, позволяла бы 
в дальнейшем объединять эти формально разные тенденции для выведения из них наиболее общих закономерных связей между внешними и внутренними факторами языка. Указанная выше диалектика между явлением действительности (внешним) и его переживанием личностью (внутренним), регулярно проявляющаяся в материалах исследований, но проявляющаяся в зависимости от материала и метода по-разному, должна находить свое объяснение с общих позиций, а не с позиций некоторой частной теоретической схемы, изобретаемой ad hoc и не позволяющей связывать их друг с другом.

Коротко говоря, общая теория ЯС нужна для того, чтобы обобщать и объяснять зависимость между внутренними (личностными) и внешними (групповыми, в пределе - общественными) факторами жизни слов. Следовательно, в рамках такой общей теории само понятие ЯС должно охватывать наиболее значимые черты ментальных лексиконов группы людей и их упорядочения (изменения) в зависимости от внешних и внутренних факторов, а также обобщенное отражение отношения индивидов к этим факторам. ЯС есть, таким образом, теоретическое обобщение таких связей и их регулярного проявления в экспериментальном языковом материале. В этом случае понятие ЯС способно выделить и зафиксировать в теоретических моделях основную закономерность, которой подчиняется язык как достояние человека, как интрапсихическое в его связи с внешними факторами, с языком как интерпсихическим. Причем ЯС должно фиксировать эту связь не субъективно-методологически (предлагая новую точку зрения на привычные явления), а объективно-методологически - как особый тип связи между личностным и социальным в языке. ЯС должно отражать не просто «социальное плюс индивидуальное», а новый тип реально существующих связей, которые состоят в том, что социальным явлениям языка придается личностное переживание, но не случайное, а закономерное. В результате личностные явления и процессы, отраженные в слове, включаются в общение как социальное явление, а социальные явления и процессы, тоже отраженные в слове, включаются в познание и переживание как личностное явление. В этом смысле всякое слово для человека есть одновременно и групповое (инструмент общения, взаимодействия), и индивидуальное (инструмент организации собственной психики). Язык вообще есть для человека не нечто постороннее, потому что социально обусловленное; напротив, это его язык именно потому, что это язык того общества (группы, коллектива), внутри которого человек живет и действует и частью которого он является. Можно представить это в виде двух пересекающихся осей (индивидуальной и групповой), но не бесконечных, а имеющих пределы. Эти пределы - крайние случаи значений некоторых слов, большинство же слов «находятся» где-то между предельными значениями, но могут «перемещаться» с изменением значений. Слово как групповое явление в пределе есть общекультурное, а в другом пределе «диалоговое», «парное», понятное только для двоих. Слово как личностное явление в пределе есть интимное, ни с кем не разделяемое, а в другом пределе - несущее общечеловеческие ценности. Эту-то личностно-социальную диалектику языка, на наш взгляд, и должно объяснять понятие ЯС.

Понятие ЯС, обладающее такой объяснительной силой, не может существовать само по себе - в отрыве от общей теории ЯС. Последняя пока еще не выработана, но жизненно необходима, чтобы, еще раз это подчеркнем, исследования ЯС не были разрозненными исследованиями отдельных его аспектов и служили бы средством обобщения и суммирования знаний о языке как достоянии человека и общества (что возможно только при едином теоретико-методологическом базисе).

Что нужно для такой общей теории ЯС?

1) теория языка, соединяющая язык как индивидуальное, как групповое и как систему (теория обобщает и фиксирует закономерности, способы представления языка как индивидуального и группового);

2) универсальные способы описания любых аспектов и форм существования объекта (объект - движение значений и личностных смыслов под действием внешних факторов);

3) принципы, из которых выводимы феноменологические свойства объекта и методологические характеристики теории.

Рассмотрим эти положения по порядку и более подробно.

Адекватная поставленной задаче теория языка существует. Это концепция Л. В. Щербы [2004], рассматривающая всё многообразие языка как выражение трех его аспектов, к кото- 
рым следует только добавить четвертый аспект - языковую организацию индивида, ментальный лексикон [Залевская, 2005. С. 32-37, 400]. Разумеется, подобная теория языка может существовать и в ином виде, но ключевым ее свойством должна являться способность соединять закономерности существования языка как социального и как индивидуального явления, учитывая, что всякое существование языка динамично. Теория языка, подходящая для теории ЯС, сможет, таким образом, соединить две динамики языка - внутреннюю (интрапсихическую) и внешнюю (интерпсихическую), а также их обобщения в теоретических абстракциях. Это должна быть теория языка, способная выводить общие закономерности движения языка как формы индивидуального сознания из наблюдаемых фактов использования языка, которые получены не от одного человека, а от некоторой группы людей. И коль скоро такие фиксируемые в теории закономерности являются общими для группы людей (они не просто одинаковые, а существенные), то они связаны с учитываемыми в теории характеристиками группы, а коль скоро это закономерности, регулярно проявляющиеся в эмпирическом материале, то они индивидуальны (т. е. имеются потенциально у всех представителей группы в той или иной форме и степени).

Язык в своей целостности предстает в таком случае не надындивидуальной системой знаков и не набором ассоциаций в конкретном индивидуальном сознании, а личностно-социальным континуумом разнообразных явлений. Такой континуум изображен на рисунке. Се-

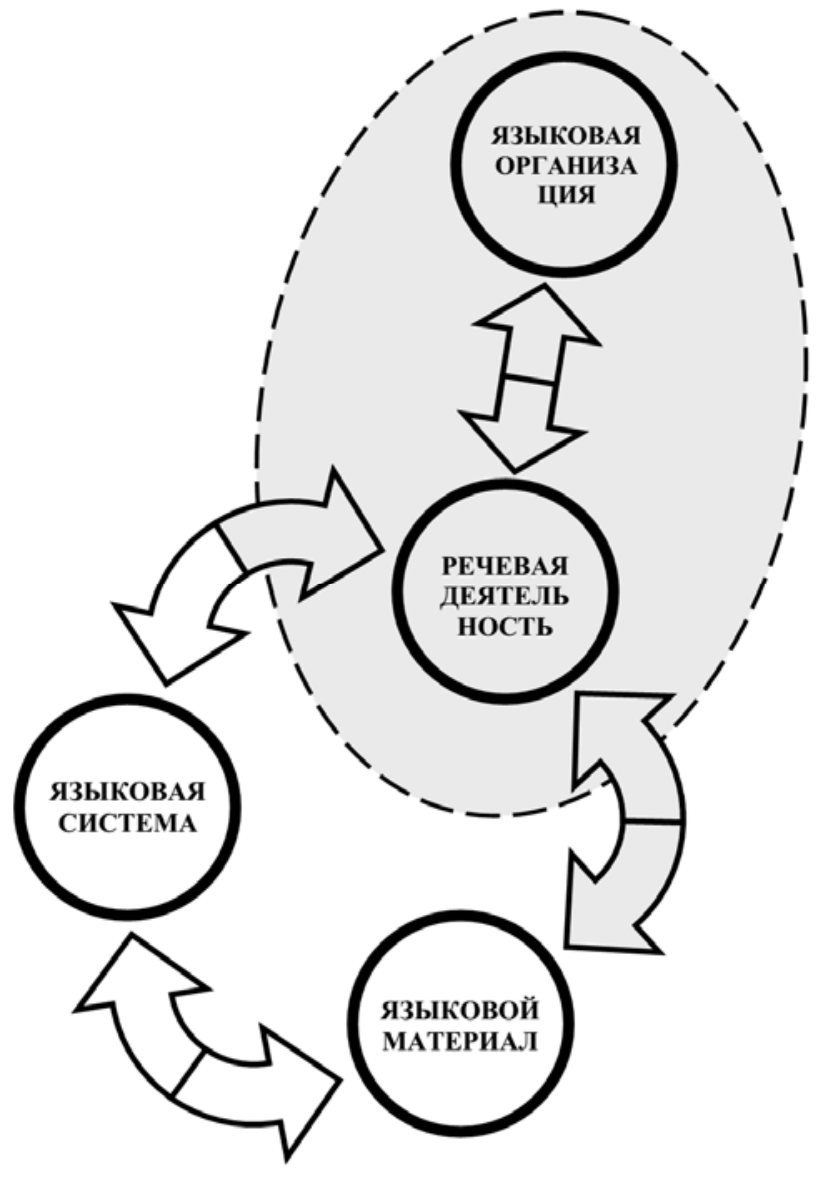

Личностно-социальный континуум языковых явлений Щербы - Залевской рым цветом обозначены языковые явления и их взаимосвязи, состоящие из совокупностей индивидуальных актов, в принципе подразумевающие конкретизацию вплоть до индивидуальных особенностей. Штриховкой обозначены индивидуальное сознание и входящие в него психические явления.

При этом в теории речь должна идти именно о теоретических обобщениях, об абстракциях, о теоретических моделях и схемах реальных явлений и процессов, а не о конкретных явлениях индивидуального сознания людей, входящих в данную группу. В положениях теории должны обобщенно отражаться закономерности взаимодействия внешних и внутренних факторов, а не частные их проявления в сознании конкретных индивидов. Из понятий теории языка, как и теории ЯС, должен быть элиминирован антропоморфизм: они должны быть связаны с сознанием человека не напрямую, не как таковые, а как общие, т. е. абстрагированные и обобщенные научным познанием, закономерности, которые в частном своем выражении могут в разной степени и форме проявляться в речевой деятельности человека и в упорядочении его ментального лексикона.

Универсальные способы описания объекта подразумевают, во-первых, охват одновременно внешнего (группового) и внутреннего (личностного) в эмпирическом материале и соответствующие методы его обработки, во-вторых, единицу анализа, способную абстрагировать из эмпирического материала связи внутреннего и внешнего аспектов языковых явлений. Единица анализа ЯС должна сохранять для дальнейшего обобщения связь внешнего и внутреннего, т. е. выраженного в слове сознательного образа и межличностного 
(группового, социального) процесса, в который данный образ через данное слово вовлечен. Вне зависимости от формы терминологического наименования (концепт, гештальт и т. п.) всякий образ сознания, связанный со словом, имеет в своем составе языковой аспект, предметный аспект, эмоционально-личностный аспект, личностный аспект и телесный аспект [Василюк, 1993]. Единица анализа ЯС, рассматриваемая как способ обобщения, должна позволять выявить через слова все эти аспекты образов сознания и их динамические связи. Единица анализа должна в таком случае пониматься не как некоторые подлежащие регистрации имманентные характеристики эмпирического материала, а как метод выявления его внутренних закономерностей, благодаря которым эмпирические факты таковы, каковы они есть в зависимости от разных условий.

Основных принципов теории, из которых выводятся феноменологические свойства объекта и методологические характеристики теории, можно назвать четыре.

Первый состоит в том, что отражение мира в сознании человека носит активный и пристрастный характер. Следовательно, в языке как особой (но не единственной!) форме существования сознания, в языковых знаках существен эмоциональный компонент. Аффективное переживание мира онтологически присуще языковому знаку, а не является некоторой «прибавкой» к значению, которая может и не учитываться. Это значит, что в эмпирическом материале в том или ином виде будет проявляться эмоционально-оценочное отношение к миру, фиксируемое и выражаемое через язык, и оно же фиксируется в положениях и понятиях теории. Каждое слово содержит в себе эмоционально-оценочный, личностный компонент; другое дело, что в некоторых случаях эмоциональное переживание может быть нейтральным или неявным и не проявляться в рамках эксперимента. В этом отношении следует говорить не о языке и сознании или о языке в сознании, но о языке как сознании.

Второй принцип: внешние воздействия преломляются через внутренние условия (в более широком гносеологическом контексте см. об этом: [Рубинштейн, 2012]). Изменение внешних (групповых) факторов языка как достояния человека, преломляясь в эмоционально-оценочном отношении, вызывает и изменение внутренних факторов, закономерности чего отражаются в эмпирическом материале и обобщаются теорией. Никакое внешнее (т. е. охватывающее всю группу индивидов) изменение само по себе не вызывает существенных изменений в ментальных лексиконах людей, а только если оно в той или иной мере переживается как личностно значимое, что тоже может находить разную степень выраженности в конкретном экспериментальном материале.

Третий принцип связан со статистическим, вероятностным характером фиксируемых в теории закономерных связей между внешними и внутренними факторами языка. В этом случае не спрашивается, например: «Какая словоформа в конкретном ментальном лексиконе имеет эмоционально-оценочную окраску?» Но спрашивается: «Какие словоформы потенциально могут иметь такую-то эмоционально-оценочную окраску в зависимости от определенных характеристик группы людей?» Невозможно предсказать поведение или свойства словоформы, можно только предсказать вероятность того, что она будет вести себя некоторым образом (не всегда строго определенным). Вероятностный подход к объяснению закономерностей языка как достояния человека не говорит нам о характеристиках конкретного слова в сознании конкретного человека. Но он говорит нам о большей или меньшей вероятности обнаружить те или иные характеристики данного слова, при этом результат нужно выводить не из одного, а из многих наблюдений. Понимание того, какими свойствами обладает слово (например, дающее в ассоциативном эксперименте такие-то типы реакций), позволяет сказать, с какой вероятностью это слово проявит в речевой деятельности выявляемые через эти типы реакций особенности своего значения. Следовательно, материал исследования может быть получен только от группы людей (множество повторных «измерений»), одна или несколько характеристик которой учитываются, а от других исследователь абстрагируется.

Четвертый принцип состоит в том, что способ познания влияет на его конечный результат. Свойства объекта даны субъекту не напрямую, а в акте познания, но способы и средства наблюдения и обобщения результатов не есть часть объекта познания и не могут включаться в результат познания. Однако они входят в итоговое знание обобщенно и косвенно, а именно в качестве особенностей знания о самом этом объекте. Характер способов познания кристаллизуется и обобщается теорией в характере знания об объекте, в специфике приписываемых 
объекту свойств (хотя и не всех). Способы познания проявляются как характеристики объекта, первые принимаются за часть последних. Этим обусловливается необходимость применять к ЯС комплекс методов, перепроверять полученные результаты, подвергать один и тот же материал разностороннему анализу.

Названные принципы кратко можно выразить так: активность и пристрастность сознания, опосредованность внешнего воздействия внутренними «фильтрами» (т. е. внешние причины действуют через внутренние условия), вероятностный характер знания свойств объекта, вовлеченность субъекта и метода познания в его конечный результат.

Работы, не реализующие эти принципы, посвящены не ЯС, если его трактовать так, как в настоящей статье. Они относятся к традиционной семантике, к лингвокультурологии, лингвоперсонологии и т. п. Таковыми являются, например, следующие исследования: [Малевинский, 2006; Прокофьева, 2008; Стефанский, 2009; Шаманова, 2009], хотя формально они претендуют на изучение именно ЯС (характерно, что в них в качестве методологической базы указывается традиционная семантика, например, в понимании ее Московской семантической школой).

Приведенный выше список принципов является открытым, и можно не сомневаться, что развитие общей теории ЯС заставит добавить в него какие-то другие и уточнить имеющиеся.

Каковы же основные положения общей теории?

Если в ментальном лексиконе имеется форма (слово), которая

- имеет значение,

- имеет личностный смысл (выражает деятельное и эмоционально-личностное переживание действительности человеком),

- имеет связь со значением предмета и / или ситуации,

- помогает человеку более эффективно осуществлять деятельность (познание и общение) в меняющемся мире,

то эта форма

о не может не быть связана с другими формами разнородными связями,

o не может не изменять связи с другими формами и другими явлениями сознания, или, выражая ту же мысль иначе, не может не двигаться в сознании под действием внутренних и внешних факторов,

o не может не содействовать другим явлениям сознания (среди которых память, мышление, воображение и т. д.) в познании мира, общении и организации поведения человека.

Поясним сформулированные положения и проиллюстрируем их примерами.

В первом положении наиболее важна разнородность связей слов и стоящих за ними образов. В эмпирии (в частности, в ассоциативном эксперименте) проявляются все аспекты образа либо некоторые из них, но никогда не бывает лишь одного.

Например:

ВРАЧ - доктор, медик, трюкач (языковой аспект), больница, бельй халат, лечит, иприц (предметный аспект), боюсь, недоучка, спасатель (эмоционально-личностный аспект), запах, боль (телесный аспект);

АРМИЯ - флот, войско (языковой аспект), форма, солдат, война (предметный аспект), зло, отчисление, маразм (эмоционально-личностный аспект);

ЧЕТВЕРГ - пятница, вторник, jueves, jeudi (языковой аспект); тупее субботы, любимый день (эмоционально-личностный аспект); рыба, учеба, тренировка, до 17:30 (семический аспект);

БИЛИНГВИЗМ - двуязычие, монолингвизм, Билли (языковой аспект); Набоков, Юра Чжан, стюардесса (предметный аспект); круто, классно, супер, мечта (эмоциональноличностный аспект); два языка, две культуры, владение двумя языками (семический аспект).

Мы отвлекаемся от того, что аспекты образа в разных случаях выражаются с разной частотой и иногда трудноразличимы; важнее в теоретическом плане то, что наличие одного аспекта образа в ассоциациях возможно только в особых случаях. Так, при предъявлении в качестве стимулов неизвестных слов реакции (если таковые имеются) проявляют чаще всего лишь один аспект образа - языковой.

Например: 
КОНГРУЭНТНОСТЬ - конгресс, кенгуру;

ТЕНЗОР - иензор, тенор;

ГЛИАЛЬНЫЙ - гениальный.

Немногочисленные однотипные связи ассоциаций со стимулом говорят о том, что образ, стоящий за данным словом (стимулом), не сформирован, не обладает эмоционально-оценочным «весом» и не задействован в познании и общении.

Второе положение говорит о том, что потенциально каждый акт познания предмета (и вообще мира) или действия с предметом изменяет внутреннюю структуру образа предмета и отношение человека к этому предмету, и это изменение может быть выявлено через соответствующее слово. Так, материалы нашего 8-этапного ассоциативного эксперимента (результаты которого пока не опубликованы) показывает, что новые знания отражаются в реакциях, но не вытесняют старые. С недельным промежутком 62-м участникам предъявлялся один и тот же список стимулов, но на некоторых этапах непосредственно перед экспериментом им давались для ознакомления небольшие тексты, эксплицирующие значение некоторых стимулов. Реакции, связанные с содержанием текстов, резко проявлялись на тех этапах, на которых предъявлялись тексты, но не исчезали полностью на следующих. Так, для стимула СТИЛЬ текст предъявлялся на 2-м и 3-м этапах, и количество реакций, по семантике связанных с текстом, было следующим: 1 этап - 0, 2 этап - 21, 3 этап - 27, 4 этап - 15, 5 этап 11, 6 этап - 14, 7 этап - 13, 8 этап - 14. Результаты этого эксперимента подтверждают, в частности, что значение слова не статично, что оно движется (т. е. изменяется качественно и количественно) в сознании человека, не подчиняясь при этом строго только внешним воздействиям или только внутренним условиям.

Закономерности такого движения и следует выяснить и обобщить в теории. Однако, как и любое движение, оно является постепенным, и в норме почти невозможно четко отграничить один «этап» такого движения от другого. Здесь требуется особая организация экспериментов, основанная на разного рода сопоставлениях, что позволит более рельефно проявиться изменениям связей внутри отдельного образа или между разными образами сознания. Если участвующим в ассоциативном эксперименте людям не знакомы такие слова, как ВИВИСЕКЦИЯ или ОККЛЮЗИЯ, то наиболее частотной будет нулевая реакция или реакция по форме (секция, википедия и иллюзия, оказия). Но если предварительно ознакомить их с этими словами посредством небольших текстов, то реакции становятся разнообразными и отражают не только информацию этих текстов (ВИВИСЕКЦИЯ - грех, вскрытие, скрещивать, ОККЛЮЗИЯ - ураган, плед, непроходимость), но и эмоционально-оценочное переживание (ВИВИСЕКЦИЯ - живодёрство, жалость, издевательство над животными). Разнообразием связей между образами сознания и внутри одного образа можно объяснить дифференциацию ассоциаций на термины языкознания, которая проявляется, например, если сравнить результаты одного эксперимента, проведенного в группе студентов-лингвистов первого и четвертого курсов [Яковлев, 2016].

Третье положение обусловлено системным строением сознания и психики. В нем утверждается, что есть нечто, интегрирующее активность различных явлений сознания, и это нечто есть личность. Из действующей и чувствующей, переживающей мир личности рождается мотив и цель познания, общения и, следовательно, осмысления мира и себя в мире, нечто, фиксируемое в знаках как психических орудиях организации взаимодействия человека с миром. Данное положение выводит теорию ЯС за ее границы, позволяя связывать исследования ЯС с исследованиями в области психологии, психосемантики, педагогики, лингвокультурологии, когнитивного терминоведения и т. д.

Сказанное заставляет сформулировать комплекс задач, стоящих перед общей теорией ЯС:

1) по тому, какие внешние и внутренние связи данного слова проявляются в эксперименте, - выявлять и объяснять связи слов, входящих в разные семантические группы, относительно соответствующих групп людей, а также выявлять закономерности изменения этих связей при изменении внешних и внутренних факторов;

2) по тому, каковы связи данной формы с другими, - выявлять ее значение, характер ее связей с предметом и ситуацией, степень и характер выражаемого ею личностно-эмоционального переживания; 
3) по тому, как изменяются связи данной формы в зависимости от внешних и внутренних факторов, - выявлять изменение ее значения, изменение ее связей с предметом и ситуацией, изменение степени и характера выражаемого ею личностно-эмоционального переживания;

4) проверять (а не только подтверждать!) данные теории ЯС данными других наук и направлений, в первую очередь психологии.

Как и комплекс сформулированных выше методологических принципов, комплекс задач общей теории ЯС тоже открыт для последующего внесения в него поправок при появлении новых эмпирических данных.

Сформулированные в статье методологические предпосылки, необходимые для теории ЯС, и сами общие ее положения могут заставить переосмыслить некоторые (или даже многие) привычные понятия, превращая их из абсолютных в относительные. Так, на наш взгляд, само понятие «языковое сознание» предстает именно в качестве относительного: такого явления, как «языковое сознание вообще», не существует, о нем необходимо говорить только относительно некоторой группы носителей данного языка. Кроме того, ЯС как научное понятие, будучи абстракцией, вообе не обладает никакой онтологией, кроме чисто научной той, которой она наделена в рамках науки о языке. ЯС непознаваема непосредственно и чувственно, ее не найти в самом языковом материале, подвергающемся изучению; ЯС есть определенные взаимозависимости разных характеристик эмпирического материала, регулярно в нем проявляющиеся и абстрагируемые из него теорией. Такой же абстракцией, как уже упоминалось, является понятие «лингвокультура».

Другой важный вывод состоит в том, что носителем языковых изменений является не сама словоформа, а те внутренние и внешние процессы, в которые она вовлечена. Значение слова определяется ими, а не информацией, которую оно переносит от человека к человеку. Понятие «значение» вообще не может быть сведено к информации, содержащейся в знаке. Семантические свойства слова не имманентны ни ему самому, ни психическим свойствам носителей языка; они обусловлены характером взаимодействия внутреннего и внешнего общностью опыта людей и общностью осмысления данного слова этими людьми, причем эта общность не абсолютна, а относительна. И значение, и смысл всегда присущи слову, различие между ними не имеет принципиального характера (так как граница между ними размыта) и обусловлено особенностями самого континуума языковых явлений. Изменения в словах и вообще язык следует описывать не через понятия, относящиеся к характеристикам самих слов, а через понятия, относящиеся к характеристикам процессов, в которые вовлечены слова.

Характеристики языка как достояния человека, фиксируемые в понятии ЯС, не заложены в словах, они возникают, воссоздаются в каждом акте использования языка в пространстве и во времени взаимодействия между словом, предметом, эмоцией (точнее: человеческим словом, человеческим предметом и человеческой эмоцией). Эти характеристики не в индивидуальном сознании человека, а между его аффективно переживающей мир личностью и его же деятельностью, с одной стороны, и миром, на который деятельность и переживание направлены, с другой. Коротко: характеристики языка, фиксируемые в ЯС, не расположены в сознании человека, а возникают между взаимодействующими человеком и миром.

Изменения связей внутри образов сознания и изменения их отражения в эмпирическом материале носят уникальный и вместе с тем системный характер. С одной стороны, изменение внешних (а следовательно, и внутренних) факторов жизни слова происходит всегда системно, меняется вся система связей между компонентами образа. С другой стороны, такие изменения уникальны для каждого слова, любое слово по-своему отражает компоненты образа сознания. Отсюда вывод: существенные закономерности изменения связей одного слова в ментальных лексиконах группы людей в зависимости от внешних и внутренних факторов и отношения индивидов к этим факторам могут не находить своего выражения или находить лишь косвенное выражение в другом слове, сколь бы близким по значению оно ни было к первому, или в другой группе людей.

Выше не приводилось определения собственно ЯС. Это сделано умышленно, поскольку мы полагаем, что исследования ЯС должны не исходить как из постулата из некоторого общего определения, выработанного посредством теоретизирования, а прийти к такому определению посредством анализа конкретных языковых фактов с возможностью последующего 
его пересмотра в свете новых фактов. Эмпирический материал должен рассматриваться таким образом, чтобы ЯС предстало как своего рода производная от внешних и внутренних факторов, влияющих на значения и смыслы слов. Тогда в ЯС как понятии теории будет фиксироваться то, каким образом внутренние (эмоции, ценности и т. п.) и внешние (возраст, профессия и т. п.) условия функционирования языка как достояния человека связаны с движением языка, с изменением значений и смыслов слова и его связей с другими словами.

\section{Список литературы}

Василюк Ф. Е. Структура образа // Вопросы психологии. 1993. № 5. С. 5-19.

Залевская А. А. Психолингвистические исследования. Слово. Текст: Избранные труды. М.: Гнозис, 2005. 543 с.

Залевская А. А. Значение слова через призму эксперимента: Монография. Тверь: Твер. гос. ун-т, 2011. $240 \mathrm{c}$.

Иноземщева Л. П. Отражение корпоративной культуры преподавателей вуза в языковом сознании носителей русской культуры: Дис. ... канд. филол. наук. Челябинск, 2012. 208 с.

Малевинский С. О. Семантические поля порока и добродетели в языковом сознании современной студенческой молодежи: Дис. ... д-ра филол. наук. Краснодар, 2006. 207 с.

Прокофьева Л. П. Звуко-цветовая ассоциативность в языковом сознании и художественном тексте: универсальный, национальный, индивидуальный аспекты: Дис. ... д-ра филол. наук. Саратов, 2008. 442 c.

Рубинштейн С. Л. Бытие и сознание. СПб.: Питер, 2012. 288 с.

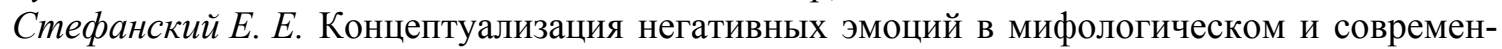
ном языковом сознании: на материале русского, польского и чешского языков: Дис. ... д-ра филол. наук. Самара, 2009. 385 с.

Уфимиева Н. В., Тарасов Е. Ф. Проблемы изучения языкового сознания // Вопросы психолингвистики. 2009. № 10. С. 18-25.

Шаманова М. В. Коммуникативная категория в языковом сознании (на материале категории «общение»): Дис. ... д-ра филол. наук. Воронеж, 2009. 534 с.

Щерба Л. В. О трояком аспекте языковых явлений и об эксперименте в языкознании // Языковая система и речевая деятельность. Изд. 2-е, стереотипное. М.: Едиториал УРСС, 2004. $432 \mathrm{c}$.

Яковлев А. А., Манхирова В. В., Случаева E. К. Репрезентация наименований некоторых профессий в языковом сознании русскоязычных студентов // Слово и текст: психолингвистический подход. Тверь: Твер. гос. ун-т, 2015. Вып. 15. С. 102-108.

Яковлев А. А., Елизарова (Телешева) С. В. Некоторые особенности языкового сознания студента: данные ассоциативного эксперимента // Вестн. Новосиб. гос. ун-та. Серия: Лингвистика и межкультурная коммуникация. 2016. Т. 14, № 4. С. 27-38.

Яковлев А. А. Терминологическая репрезентация научной картины мира в языковом сознании студента // Вопросы когнитивной лингвистики. 2016. № 3. С. 62-68.

Яковлев A. А. Модальность и эмоции в вербализации образов преподавателя и студента // Вестн. Новосиб. гос. ун-та. Серия: Лингвистика и межкультурная коммуникация. 2017. Т. 15, № 3. C. 5-20. 


\author{
Andrey A. Yakovlev \\ Siberian Federal University \\ 82a Svobodny Ave., Krasnoyarsk, 660041, Russian Federation \\ mr.koloboque@rambler.ru
}

\title{
LINGUISTIC BASIS FOR THE GENERAL THEORY OF THE LINGUISTIC CONSCIOUSNESS
}

The paper discusses the theoretical and methodological prerequisites for the creation of a general theory of linguistic consciousness, including a set of experiments capable of testing it and possibly of verifying the validity of some of its points. The main idea of such a theory of linguistic consciousness is a parallel and interconnected analysis of external (social) and internal (personal) factors in their way to impact language which must be viewed from the anthropocentric perspective. A general theory of linguistic consciousness should incorporate: 1. a theory of language as an individual phenomenon, as a group one and as an abstract scientific semiotic system; 2 . universal methods of describing any aspects and forms of existence of an object; 3. principles from which the phenomenological properties of the object and the methodological characteristics of the theory are deduced. The provisions of the theory and the underlying experimental research will allow us to determine how the internal (emotions, values, etc.) and external (age, profession, etc.) conditions will cause changes of the word meanings and of their interconnections.

Keywords: linguistic consciousness, anthropocentric linguistics, psycholinguistics, meaning, sense.

\section{References}

Goroshko E. I. Jazykovoe soznanie: Associativnaja paradigma [Linguistic consciousness: associative paradigm]. Thesis ... Doctor of Linguistics. Moscow, 2001, 287 p. (in Russ.)

Inozemtseva L. P. Otrazhenie korporativnoj kul'tury prepodavatelej vuza v yazykovom soznanii nositelej russkoj kul'tury [Reflection of the University corporate culture in the linguistic consciousness of Russians]. Thesis ... Doctor of Linguistics. Cheljabinsk, 2012, 208 p. (in Russ.)

Malevinskij S. O. Semanticheskie polya poroka i dobrodeteli v yazykovom soznanii sovremennoj studencheskoj molodyozhi [Semantic fields of vice and virtue in the linguistic consciousness of modern students]. Thesis ... Doctor of Linguistics. Krasnodar, 2006, 207 p. (in Russ.)

Prokof'eva L. P. Zvuko-tsvetovaya assotsiativnost' v yazykovom soznanii i khudozhestvennom tekste: universal'nyj, natsional'nyj, individual'nyj aspekty [Colour-sound associations in the linguistic consciousness and literary text]. Thesis ... Doctor of Linguistics. Saratov, 2008, 442 p. (in Russ.)

Rubinshtejn S. L. Bytie i soznanie [Being and consciousness]. St. Petersburg, Piter, 2012, 288 p. (in Russ.)

Shamanova M. V. Kommunikativnaya kategoriya v yazykovom soznanii (na materiale kategorii «obshhenie») [Communicative category in the linguistic consciousness (on the material of category "communication")]. Thesis ... Doctor of Linguistics. Voronezh, 2009, 534 p. (in Russ.)

Shcherba L. V. O troyakom aspekte yazykovykh yavlenij i ob eksperimente v yazykoznanii [On threefold aspect of language phenomena]. Yazykovaya sistema i rechevaya deyatel'nost' [Linguistic activity and speech activity]. Moscow, Editorial URSS, 2004, 432 p. (in Russ.)

Stefanskij E. E. Kontseptualizatsiya negativnykh emotsij v mifologicheskom i sovremennom yazykovom soznanii: na materiale russkogo, pol'skogo i cheshskogo yazykov [Conceptualisation of the negative emotions in mythological and modern linguistic consciousness]. Thesis ... Doctor of Linguistics. Samara, 2009, 385 p. (in Russ.)

Ufimtseva N. V., Tarasov E. F. Problemy izucheniya yazykovogo soznaniya [Problems of the linguistic consciousness research]. Voprosy psikholingvistiki [Journal of Psycholinguistics], 2009, no. 10, p. 18-25. (in Russ.)

Vasilyuk F. E. Struktura obraza [Image structure]. Voprosy psikhologii [Questions of Psychology], 1993, no. 5, p. 5-19. (in Russ.) 
Yakovlev A. A. Modalnost' i emotsii pri verbasizatsii obrasov prepodavatelya i studenta [Modality and Emotions in the Verbalization of the Images of a Teacher and a Student]. Vestnik Novosibirskogo gos. un-ta [Vestnik NSU. Series: Linguistics and Intercultural Communication], 2017, vol. 15, no. 3, p. 35-43. (in Russ.)

Yakovlev A. A., Elizarova (Telesheva) S. V. Nekotorye osobennosti yazykovogo soznaniya studenta: dannye assotsiativnogo eksperimenta [Some aspects of stdents' language consciousness: associative experiment]. Vestnik Novosibirskogo gos. un-ta [Vestnik NSU. Series: Linguistics and Intercultural Communication], 2016, vol. 14, no. 4, p. 27-38. (in Russ.)

Yakovlev A. A. Terminologicheskaya reprezentatsiya nauchnoy kartiny mira $\mathrm{v}$ yazykovom soznanii studenta [Scientific worldview through the linguistic terms in the student's mental lexicon]. Voprosy kognitivnoy lingvistiki [Questions of Cognitive Linguistics], 2016, no. 3, p. 62-68. (in Russ.)

Yakovlev A. A., Mankhirova V. V., Sluchaeva E. K. Reprezentatsiya naimenovanij nekotorykh professij v yazykovom soznanii russkoyazychnykh studentov [Representation of certain profession names in the language consciousness of the Russian students]. Slovo i tekst: psikholingvisticheskij podkhod [Word and text: psycholinguistic approach]. Tver', Tver. gos. un-t, 2015, no. 15, p. 102108. (in Russ.)

Zalevskaya A. A. Psikholingvisticheskie issledovaniya. Slovo. Tekst: Izbrannye trudy [Psycholinguistic researches. Word, text: Selected works]. Moscow, Gnozis, 2005, 543 p. (in Russ.)

Zalevskaya A. A. Znachenie slova cherez prizmu eksperimenta [Word meaning through the experiment prism]. Monograph. Tver', Tver. gos. un-t, 2011, 240 p. (in Russ.)

\section{For citation:}

Yakovlev Andrey A. Linguistic Basis for the General Theory of the Linguistic Consciousness. Vestnik NSU. Series: Linguistics and Intercultural Communication, 2018, vol. 16, no. 3, p. 45-55. (in Russ.)

DOI 10.25205/1818-7935-2018-16-3-45-55 